\title{
Review of Different Tools and Technologies to Assist Visually Impaired Persons
}

\author{
Irfan Hussain, Abdul Manan, Aneela Mazhar and Umar Shoaib \\ Department of Information Technology, Faculty of Computer Science and Information Technology, University \\ of Gujrat, Gujrat - 50700, Punjab, Pakistan; awan.irfan@live.com, mananjatt@hotmail.com, \\ csit_096@yahoo.com,umar.shoaib@uog.edu.pk
}

\begin{abstract}
Objectives: This paper presents the overview of five different tools and techniques for visually impaired, namely Braille Touch, Online Multi language Word Processor, Helping Hand, Sound Game and Readable Image. Methods: This is not a comparison of the tools, so each of the tool or technology was studied separately in terms of its design and working, merits and de-merits the experiments and evaluation etc. Findings: Braille Touch is a software-based technology and is very cheap and user friendly as compared to other available Braille Technologies. But, it can't be implemented on Ordinary cell phones and needs touch devices. The Sound Game works automatically so it can be used by single user without any assistance. It can be used at home or small space because of compact size. Online Multi language Word ProcessorInterface was very simple and light colors were used to assist the color blinds but Translation and Transliteration were done using Google API that doesn't provide accurate results. System is not evaluated to check the performance and popularity. Readable Image provides accessibility and readability of images at different levels of detail to the persons having visual impairments while previous tools could only read the image by its caption and tags.Helping Hand device is portable and very easy to use. The device was tested on a small group so the results cannot be considered satisfactory. Improvements: The Braille Touch device needs to be evaluated. More functions can be added in Sound Game and Online Multi language Word Processor. The approach for the Readable Image will be implemented.
\end{abstract}

Keywords: Braille, Tools, Technologies, Visually Handicap, Visually Impaired

\section{Introduction}

In this technological age, everyone has to rely on computer based systems to perform routine tasks.. Now days, with the advancements in $\mathrm{HCI}^{2}$, the systems are designed in terms of usability ${ }^{3}$. There are variety of hardware tools and software programs available to assist user to accomplish different tasks. But the main problem is that these systems are designed for the common audience and those having disabilities are not able to take full advantage of these systems. The persons with visual impairments ${ }^{4}$ suffer the most.

According to World Health Organization report, 285 Million people are visually impaired worldwide ${ }^{5}$. Majority of these, about 90 percent live in developing countries ${ }^{5}$. There is a need of designing and developing assistive systems and technologies for such a majority of disable ones.

Visually impaired persons are able to use computer system by audio and tactile feedbacks. Screen Readers are special software that converts written text or commands into human speech. JAWS, VoiceOver, Window-Eye, NVDA and System Access are the commonly used screen readers among them JAWS is the most preferred one ${ }^{6}$. The screen magnification software enables disabled computer users to enlarge the monitor output so the details become more clear and visible. Human Ware's ${ }^{7}$ Text Magnifiers and Braille Tools are great assets for the visually impaired. Tactile devices provide tactile feedbacks e.g. vibrations that can be sensed by the visually impaired. Different

*Author for correspondence 
latest Mice by Logitech $\stackrel{8}{ }$ are an example of tactile devices. Most of the modern tools and technologies for visually impaired use audio-tactile feedback.

This paper presents the review of different tools and techniques developed recently to assist the visually impaired. These include Braille Touch ${ }^{9}$ mobile phone software used for text messaging, Online Multi language Word Processor ${ }^{10}$ a word processor used for translation and transliteration purpose, Helping Hand ${ }^{11}$ an RFID based glove for same sized object identification for visually impaired, Sound Game ${ }^{12}$ to help in exercise and Readable Image ${ }^{\frac{13}{3}}$ for image interpretation at different levels of detail.

Section 2 contains the background work. In Section 3 each tool is discussed in terms of working and performance. Section 4 provides discussions and merits and de-merits of each tool. Conclusion and future work is given in Section 5.

\section{Background Work}

In 1829, Louis Braille developed procedure for writing for the blind ${ }^{14}$. Since that time efforts have been made to design such systems that will help blind and visually impaired to perform their routine tasks in an easy way. In 1885, William Perkins invented a typewriter like machine that was called Writing-Machine for the Blind ${ }^{15}$. The "white cane" 16 explained that by painting his cane white, one will be more visible to the vehicle drivers. These white canes were sold out by Royal National Institute of Blind People in 1932 as a way finder aid for the visually impaired and blind ${ }^{17}$. In 1958, Charles Strunk proposed a Writing Guide for the blind and visually impaired ${ }^{18}$. The first mobile phone specifically designed for the visually impaired was introduced in start of this century ${ }^{19}$.

Since last two decades, a lot of work has been done to develop tools and technologies for the visually impaired. Different type of Navigation Systems $\mathrm{s}^{\underline{20}-\underline{23}}$ various games ${ }^{25}-\underline{29}$, Educational Systems $\mathrm{s}^{30, \underline{31}}$ and mobile applications ${ }^{32}$ has been developed for the disable ones.

\section{Tools and Technologies}

In this section, the design, working and performance based evaluation of the following fivetools and technologiesare discussed.
- Braille Touch: Mobile phone software used for text messaging

- Tracking Sound Game:An audio feedback game for Exercise support

- Online Multi language Word Processor: A multilingual word processor having translation and transliteration features.

- Readable Image: Software interface for image interpretation at different levels of detail.

- Helping Hand: An RFID based glove for same sized object identification.

\subsection{Braille Touch}

BrailleTouch is a software technology that helps visually impaired users to send text messages using touch screen mobile devices. It also provides audio feedback while each character is selected.

Design and Working: The main interface is very simple, there are six buttons on the interface and the user doesn't need to move his fingers once set. The user has to grasp the device in a posture that the screen is from them. There are tactile Braille characters on the back side of the casing to assist the user to guessthe exact location of the keys. Convenient Braille technology has a space bar button and a back space on it while in this technology, big spacebar button is kept at center of screen and the backspace is the combination of spacebar and button 6 . Each character is associated with a small sound file of the length quarter of a second that is played while each character is pressed.

Experiments and Evaluation: This technology was evaluated by different experts and their feedback was very encouraging. It was suggested to change the case in a way that user gets in mind how to operate the device. Because most of the users have intentions to use the device screen facing towards them but here the situation is opposite. Two visually impaired persons also evaluated the technology; one of them was fluent in Braille. Both found this technology very helpful and easy to use. The Braille user also confirmed that this technology is so much cheaper than Braille in terms of cost.

The evaluation interviews also encouraged this technology to be used as a powerful teaching tool for visually impaired. Two visually impaired Braille instructors were interviewed for this purpose. Their feedback was 
very positive and they suggested implementing this technology in area of special education ${ }^{33}$. The instructors also participated in tests and the results were very satisfactory, about 30 to 50 words/Minute. From these interviews it was observed that the use of thumb in Braille users is minimal, because of less sensitivity of the thumb skin. So the tactile Braille characters on the back of device casing are not necessary.

Findings: The device was tested on many platforms and it proved to be the reliable and least expensive hardware option as compared to the available Braille readers. In Terms of software functionality, BrailleTouch gave very good performance. This technology can be easily implemented on mostly used mobile platforms e.g. Android, Apple etc.

\subsection{Tracking Sound Game}

This isan Exercise Support System designed for the visually handicapped. A person with visual impairment can use this system alone at home. The system combines the audio game effects through headphones so the user doesn't gets bored while exercising.

Design and Working: The system design is simple; there is a bicycle shaped device with pedals and steering wheel used for the exercise purpose. This device is controlled by a computer. Data e.g. the rotation of pedals and the degree of leaning of the wheel is sent to the controlling PC. Computer interprets this data and generates sounds according to that data. The user receives these sound files through the headphones.

The user rides the device wearing the headphones, he is given a target to chase, (a sound produced by the PC). Here the roar of Lion and Maracas sound are used as target. User rotates the pedals and wheel to chase the target. When the target is achieved, the score is announced and the new target is presented. There are different targets to complete a stage and after completing three stages, the final score, the rank and the total distance covered is announced.

Evaluation and Results: The system was evaluated by conducting experiments with 20 subjects. 7 out of them were totally blind, 5 having amblyopia ${ }^{34}$ and 8 were without any impairment. Five point scale questionnaire were performed. The results of these questionnaires focusing on fun proved that the system was very much enjoyable for both the impaired and unimpaired ones.
On the basis of these results, different improvements were made. Different functions were added e.g. Ranking function, function that will increase the difficulty level when the user plays the game well, function for reverse paddling. Various newmodes of game and sounds e.g. Sheep bleats and Dog barks were also added. Target sound locations were made difficult to guess and time to chase the target was also shortened.

After these improvements, the system was re-evaluated. This time the system was fixed in a school and seventeen students used it for two months. Again the log data was collected and the questionnaires were made. The results showed that the system needs more improvements for gaining continuity. The system was considered as so much fun.

Through initial and after experimental evaluation, it was seen that the system proved to be enjoyable resource for continued exercise for the visually impaired.

\subsection{Multi-Language Online Word Processor}

Multi-language Online Word Processor is web based word processing software that can perform translation, transliteration and speak the typed words in various languages. This is completely free and is designed to assist the users having visual impairments or learning new languages.

Features: The system provides various nice features like Translation, Transliteration, Speech Synthesis, Text formatting, Keyboard controls and document downloading and emailing.

Text to Speech $\frac{35}{3}$ is the most prominent function of the system for the visually impaired ones. Each word is pronounced when it is typed. It is also helpful for the language learners to pronounce the word accurately. The document can be formatted and is saved automatically if the user is logged on to his account. Otherwise it is saved in server cache.

Document sharing is also possible either by downloading the document or forwarding as email. System can be operated by the combination of different keys of keyboard that makes it very adoptive for the visually handicapped ones.

System Design and Interface: The system interface is designed using HTML and AJAX. PHP is used at backend to communicate between interface and speech synthesis and recognition engines. 
Speech engines are installed on Linux server and use Festival speech synthesis system ${ }^{36}$. Translation and Transliteration functions are performed using Google API like Google translator and Google Transliteration services.

Interface is kept very simple by using shades of gray color as Background. There is a large menu button for adjusting the color and size of the buttons especially for visually impaired ones. The selected options are highlighted by invert colors so it is easy to discriminate from the unselected ones.

In many operating systems, there exists issue of missing font. This can be resolved by using different methods. Two of them, Cufon ${ }^{37}$ and SIFR ${ }^{38}$ are discussed in this paper. Adobe Flash ${ }^{39}$ is also referenced to solve the complex scripts issue.

Findings: The system was designed using open source platforms like PHP, HTML, and AJAX. Google API's were used for translation and transliteration purposes. System will be implemented and evaluated in the future.

\subsection{Readable Image}

It is a method that makes any image accessible to be read by the people having visual impairments. This is a multi level approach that allows a person to choose the level of description and the sequence they wish. Image can be viewed at different level of details.

Design and working: The approach is designed in two parts, at first part; the description associated with the image is built and organized with an expressed view. Image is annotated at different levels and each level provides the description associated to it. The detailed level provides the detail of each point of the image whereas the broader levels provide only the gross details of all the pixels. The other part is designing the interface that enables the user to navigate the image by hovering on the mouse on it and selecting different levels by scrolling the mouse. The mouse pointer position is recorder as $(\mathrm{x}, \mathrm{y})$ and all the details are provided according to that position. The speech synthesis engine then reads that description.

Almost all formats of images can be read by this approach. Multilevel description is captured as text file. Full level details of each point are captured by identifying the color of each pixel. So the level 1 provides the description of each pixel. At level 2, the description is achieved by grouping the pixels of same properties e.g. same texture. Same pixel may have different description at different levels. This description is then stored in text file and is kept separate from the image file.

Multilevel description is assessed by the position of the cursor on image. When the cursor is on a particular area of image, its location is determined and level is identified. Then the text between $<$ des $>$ and $</$ des $>$ tags corresponding to the level and pointer location is obtained from the description text file. This description is then read out by the text to speech software. Levels are controlled by the mouse scrolling.

Findings: The method proposed by the writer not only allows a user to access images but the information about the image can also be accessed in desired order and level.

\subsection{Helping Hand}

The design and evaluation of "Helping Hand", an RFID ${ }^{40}$ glove that can identify different objects of same size audibly by reading the tags, was presented $\mathrm{in}^{12}$. The effectiveness was evaluated by three-arm control study. Three technologies including "Baseline", "Helping Hand" and "ERSP" were compared by experiments.

System Components and working: Helping Hand consists of three main components, Microcontroller main board, RFID Antenna and Digital Sound Shield. "ArduinoDuemilanove" 41 main board was used in this system. The software that controlled the board was written in "Wiring" ${ }^{42}$. "Parallax" low frequency serial RFID reader was used.

The main board is programmed so it can recognize different tags from the RFID antenna. When a Message is received, it is first validated and then associated with a wave file already saved in sound card. That Wave file is then played as feedback. The battery along with board is kept on backside of the glove pocket for user's comfort.

The RFID antenna is attached to the main board and can send serial data at speed 2400 bps. It can detect HF passive tag from the distance of 2-3 inches away from the antenna. The antenna is kept at back of the palm.

The sound shield is for providing audio feedback. It is connected to main board and has options to insert SD/ MMC card. There are 16 bits audio files stored in SD card. These are programmed and associated to different tags. On receiving a message, the corresponding audio file is played as feedback. There is an audio jack for headphones.

Evaluation and Experiments: For the evaluation of effectiveness of system, a within-subject test design was 
conducted. Subjective data was also collected by the participants through a questionnaire.

Seven visually impaired persons including 3 males and 4 females were gone through the test. For this activity, the object that was chosen randomly was presented to the subject on a table. The subject was instructed how to use the identification method and was asked to identify the object. Each of the identification method was tested four times. Each time the object was selected randomly. The objects were classified in four groups. First group contained bottles of soda in different flavors, the other groups have medicine bottles, cereals and non-toxic agents.

Two approaches were used to measure the objective and subjective results. For objective purpose, a stop watch was used and the time for each subject to identify the correct object was recorded. For subjective purpose, The Likert Scale ${ }^{\underline{43}}$ was used based on four opinion questions scored on a seven point scale. Participants were asked to rank the testing methods on the basis of following criteria, simplicity, practicality, predictability and preference.

Results: For each participant, the object recognition time was measured and it was shown that 6 out of 7 participants improved recognition time while using Helping Hand or ERSP. For 5 subjects, Helping Hand proved to be the best.

The Likert survey results also proved that Helping Hand was the more simple to use, practical, predictable and preferred device.

Findings: A new RFID based glove was designed and evaluated by using objective and subjective methods. The results of analysis proved this device best among other existing technologies e.g. ERSP and Baseline in terms of performance, simplicity and predictability.

\section{Discussions}

Braille Touch technology will surely help the visually impaired persons to get advantages of SMS services. It is software based technology and is very cheap as compared to other available Braille Technologies. The interface is user friendly. It can be easily implemented on current mobile platforms e.g. android, iOS. It can be used as a powerful teaching tool for the visually impaired.

On the other hand, this software system has the limitations as it can't be implemented on Ordinary cell phones, and needs touch devices. The user is asked to hold the device screen away from him that is not common practice so it needs additional operational guidance.

Sound Game works automatically so it can be used by single user without any assistance. It can be used at home or small space because of compact size. The improved system provides more functionality as compared to the original.

Online Multi language Word Processor Interface was very simple and light colors were used to assist the color blinds. Menu Button was resizable and colors can be changed easily. An Open Source speech synthesis tool "Festival" was used that has capability to add new language modules. User was easily able to format, save and forward the documents. Whole system can be controlled by the Keyboard by combining different keys. That is very helpful for the users having visual impairments. On the other side, Translation and Transliteration were done using Google API that doesn't provide accurate results especially when user's focus is to learn a new language. System is not evaluated to check the performance and popularity. The desired language module needs to be added in "Festival" before starting Text to Speech services.

Readable Imageprovides accessibility and readability of images at different levels of detail to the persons having visual impairments while previous tools could only read the image by its caption and tags. The user can easily select level of details by hovering on the image and scrolling the mouse. Description is not attached to the image in audio form but it is kept separate in text file. The approach provides user friendly interface.

Helping Handdevice performed best as compared to the other two while tested on a small group of population. Both the objective and subjective methods were used to evaluate the device.It is portable and very easy to use. The device was tested on a small group so the results cannot be considered satisfactory.

\section{Conclusion and Future work}

This paper presented the overview of five recent tools and techniques for visually impaired, namely Braille Touch, Online Multi language Word Processor, Helping Hand, Sound Game and Readable Image. The design and working of each tool was discussed in detail. At the end, the merits and de-merits of each technique were discussed. From this discussion, it was shown that these devices are very helpful for the targeted audience; although some of 
this e.g. Readable Imagehave not been implemented or evaluated yet but this will definitely have good impact in near future.

In future, many improvements are aimed to be made to get the most from these technologies. The behavior of Braille Touch device needs to be evaluated. The parameters like typing speed and accuracy of the operator need to be assessed. The design of the device can also be changed for the comfort of user and easy griping. More functions can be added in Sound Game. Import/Export Function, on line spell check and Grammar check can be added in Online Multi language Word Processor. The approach for the Readable Image will be implemented.

Beside these techniques, more work has to be done yet to demolish the difference between common audience and those with disabilities. So the persons with disabilities will be able to enjoy the true taste of the modern technology.

\section{References}

1. Beauvisage T. Computer usage in daily life. Proceedings of the SIGCHI conference on Human Factors in Computing Systems; 2009. p. 575-84. https://doi. org/10.1145/1518701.1518791

2. Karray F, Alemzadeh M, Saleh JA, Arab MN. Human-computer interaction: Overview on state of the art. International Journal on Smart Sensing and Intelligent Systems. 2008; 1(1):1-23. https://doi.org/10.21307/ijssis-2017-283

3. Gould JD, Lewis C. Designing for usability: Key principles and what designers think. Communications of the ACM. 1985 Mar; 28(3):300-11. https://doi.org/10.1145/3166.3170

4. Arditi A, Rosenthal B. Developing an objective definition of visual impairment. Proceedings of Vision 96: International Low Vision Conference; 1998. p. 331-4.

5. World Health Organization [Internet]. [cited 2018 Feb 02]. Available from: http://www.who.int.

6. World Health Organization [Internet]. [cited 2017 Oct]. Available from: Vision impairment and blindness. http:// www.who.int/mediacentre/factsheets/fs282/en/.

7. WEB AIM: Screen Reader User Survey Results [Internet]. [cited 2017 Dec 21]. Available from: http://webaim.org/ projects/screenreadersurvey $2 /$.

8. Humanware [Internet]. [cited 2018 Feb 13]. Available from: http://www.humanware.com/en-international/home.

9. Add a New Dimension to the Human-Computer Interface [Internet]. [cited 2014 Nov 06]. Available from: https:// cacm.acm.org/news/180194-animals-add-a-new-dimension-to-human-computer-interaction/fulltext.
10. Frey B, Southern C, Romero M. Braille touch: Mobile texting for the visually impaired. International Conference on Universal Access in Human-Computer Interaction. Springer, Berlin, Heidelberg; 2011. p. 19-25. https://doi. org/10.1007/978-3-642-21666-4_3

11. Hasan SI. Multi-language online word processor for learners and the visually impaired. International Conference of Design, User Experience, and Usability. Springer, Berlin, Heidelberg; 2011. p. 256-60. https://doi.org/10.1007/9783-642-21675-6_30

12. Lawson MA, Do EY, Marston JR, Ross DA. Helping hands versus ERSP vision: Comparing object recognition technologies for the visually impaired. International Conference on Human-Computer Interaction. Springer, Berlin, Heidelberg; 2011. p. 383-8. https://doi.org/10.1007/978-3-642-22098-2_77

13. Ikegami $Y$, Ito $K$, Ishii $H$, Ohkura M. Development of a tracking sound game for exercise support of visually impaired. Symposium on Human Interface, Springer, Berlin, Heidelberg; 2011. p. 31-5. https://doi.org/10.1007/978-3642-21669-5_4

14. Kopparapu SK. Readable image for the visually impaired. International Conference on Universal Access in HumanComputer Interaction. Springer, Berlin, Heidelberg; 2011. p. 136-45. https://doi.org/10.1007/978-3-642-21657-2_15

15. Braille L. Procedure for writing words, music and plain song using dots for the use of the blind and made available to them. Royal Institution of Blind Youth, Paris; 1829.

16. Writing-Machine for the Blind. U.S. Patent \#329,675 [Internet]. [cited 2010 Aug 26]. Available from: http:// atwiki.assistivetech.net/index.php/1885.

17. Sight Loss - FAQs. Royal National Institute of Blind People [Internet]. [cited 2017 Oct 16]. Available from: https:// directory.hertfordshire.gov.uk/kb5/hertfordshire/directory/service.page? $\mathrm{id}=\mathrm{kBkmlaZQaPY}$.

18. Sight Loss - FAQs. Royal National Institute of Blind People; 2008 Jan 21.

19. Writing Guide for the Blind. U.S. Patent \#2,913,836; 1959 Nov.

20. UK debut for 'blind' mobile [Internet]. [cited 2013 Nov 03]. Available from: http://news.bbc.co.uk/2/hi/technology/3226314.stm.

21. Golledge RG, Loomis JM, Klatzky RL, Flury A, Yang XL. Designing a personal guidance system to aid navigation without sight: Progress on the GIS component. International Journal of Geographical Information System. 1991 Jan; 5(4):373-95. https://doi.org/10.1080/02693799108927864

22. Ju JS, Ko E, Kim EY. EYE Cane: Navigating with camera embedded white cane for visually impaired person. Proceedings of the 11th international ACM SIGACCESS 
Conference on Computers and Accessibility; 2009 Oct. p. 237-8. https://doi.org/10.1145/1639642.1639693

23. Helal A, Moore SE, Ramachandran B. Drishti: An integrated navigation system for visually impaired and disabled. Proceedings. Fifth International Symposium; 2001. p. 14956.

24. Ivanov R. RSNAVI: An RFID-based context-aware indoor navigation system for the blind. Proceedings of the 13th international conference on computer systems and technologies; 2012 Jun. p. 313-20. https://doi. org/10.1145/2383276.2383322

25. Wang Q, Levesque V, Pasquero J, Hayward V. A haptic memory game using the STRESS 2 tactile display. CHI'06 extended abstracts on Human factors in computing systems; 2006 Apr. p. 271-4. https://doi. org/10.1145/1125451.1125510

26. Miller D, Parecki A, Douglas SA. Finger dance: A sound game for blind people. Proceedings of the 9th International ACM SIGACCESS conference on Computers and accessibility; 2007 Oct. p. 253-4. https://doi. org/10.1145/1296843.1296898. PMCid:PMC2733528

27. Ishii H. Development of a game for the visually impaired. 16th World Congress on Ergonomics (IEA2006); 2006.

28. Ntoa S, Adami I, Prokopiou G, Antona M, Stephanidis C. A-cross: An accessible crossword puzzle for visually impaired users. In International Conference on Universal Access in Human-Computer Interaction, Springer, Berlin, Heidelberg; 2011 Jul. p. 342-51. https://doi.org/10.1007/978-3-642-21663-3_37

29. Ntoa S, Adami I, Prokopiou G, Antona M, Stephanidis C. A-cross: An accessible crossword puzzle for visually impaired users. In International Conference on Universal Access in Human-Computer Interaction Springer, Berlin, Heidelberg; 2011 Jul. p. 342-51. https://doi.org/10.1007/978-3-642-21663-3_37

30. Li Y, Johnson S, Nam C. Haptically enhanced user interface to support science learning of visually impaired. International Conference on Human-Computer Interaction Springer, Berlin, Heidelberg; 2011 Jul. p. 68-76. https://doi. org/10.1007/978-3-642-21619-0_10
31. Leporini B, Buzzi M. Learning by e-learning: breaking down barriers and creating opportunities for the visually-impaired. In International Conference on Universal Access in Human-Computer Interaction Springer, Berlin, Heidelberg; 2007 Jul. p. 687-96. https://doi.org/10.1007/978-3-540-73283-9_75

32. Krajnc E, Feiner J, Schmidt S. User centered interaction design for mobile applications focused on visually impaired and blind people. Symposium of the Austrian HCI and Usability Engineering Group Springer, Berlin, Heidelberg; 2010 Nov. p. 195-202. https://doi.org/10.1007/978-3-642-16607-5_12

33. Goodman L. Time and learning in the special education classroom. SUNY Press; 1990.

34. Webber AL, Wood J. Amblyopia: Prevalence, natural history, functional effects and treatment. Clinical and Experimental Optometry. 2005 Nov; 88(6):365-75. https://doi.org/10.1111/j.1444-0938.2005.tb05102.x. PMid:16329744

35. Dutoit T. An introduction to text-to-speech synthesis. Springer Science and Business Media; 1997. https://doi. org/10.1007/978-94-011-5730-8

36. Black A, Taylor P, Caley R, Clark R. The festival speech synthesis system; 1998.

37. Schwarz A. The Future of SEO: Inline SVG Fonts; 2010.

38. Introducing sIFR: The healthy alternative to browser text [Internet]. [cited $2004 \mathrm{Aug}$ ]. Available from: http://mikeindustries.com/blog/archive/2004/08/sifr.

39. Adobe Flash Player [Internet]. [cited 2017 Oct 03]. Available from: https:/helpx.adobe.com/acrobat/using/flash-playerneeded-acrobat-reader.html.

40. RFID Journal [Internet]. [cited 2017 Sep 10]. Available from: https://en.wikipedia.org/wiki/RFID_Journal.

41. Arduino Duemilanove [Internet]. [cited 2017 Apr 26]. Available from: https://www.computerhope.com , Dictionary > D - Definitions.

42. Wiring [Internet]. [cited 2017 Jun 05]. Available from: http://wiring.org.co/.

43. Albaum G. The Likert scale revisited: An alternate version. Journal of the Market Research Society. 1997 Apr; 39(2):331-2. https://doi.org/10.1177/147078539703900202 